\title{
Functional Profile of the Isolated Uremic Nephron
}

\author{
ROLE OF COMPENSATORY HYPERTROPHY IN THE CONTROL OF \\ FLUID REABSORPTION BY THE PROXIMAL STRAIGHT TUBULE
}

\author{
Leon G. Fine, Walter Trizna, Jacques J. Bourgoignie, and \\ Neal S. Bricker, Department of Medicine, Division of Nephrology, \\ University of Miami School of Medicine, Miami, Florida 33152
}

\begin{abstract}
A B S T RACT An in vitro approach to the study of single nephron function in uremia has been employed in evaluating the control of fluid reabsorption by the renal superficial proximal straight tubule (PST). Isolated segments of PSTs from the remnant kidneys of uremic rabbits (stage III) were perfused in vitro and their rate of fluid reabsorption compared with normal PSTs and with PSTs derived from the remnant kidneys of nonuremic rabbits (stage II). All segments were exposed to a peritubular bathing medium of both normal and uremic rabbit serum thereby permitting a differentiation to be made between adaptations in function which are intrinsic to the tubular epithelium and those which are dependent upon a uremic milieu.

Compared with normal and stage II PSTs, there was significant hypertrophy of the stage III tubules as evidenced by an increase in length and internal diameter, and a twofold increase in the dry weight per unit length. Fluid reabsorption per unit length of tubule was $70 \%$ greater in stage III than in normal and stage II PSTs, and was closely correlated with the increase in dry weight. Substitutions between normal and uremic rabbit serum in the peritubular bathing medium did not affect fluid reabsorption significantly in any of the three groups of PSTs. Perfusion of the tubules with an ultrafiltrate of normal vs. uremic serum likewise failed to influence the rate of net fluid reabsorption.
\end{abstract}

It has previously been observed that net fluid secretion may occur in nonperfused or stop-flow perfused normal rabbit PSTs exposed to human uremic serum. Additional studies were thus performed on

Dr. Fine is the recipient of a Research Career Development Award from the National Institutes of Health. Dr. Bourgoignie is an investigator of the Howard Hughes Medical Institute.

Received for publication 8 August 1977 and in revised form 30 January 1978. normal and stage III PSTs to evaluate whether net secretion occurs in the presence of rabbit uremic serum. No evidence for net secretion was found.

These studies demonstrate that fluid reabsorption is greatly increased in the superficial PST of the uremic remnant kidney and that this functional adaptation is closely correlated with compensatory hypertrophy of the segment. Humoral factors in the peritubular environment do not appear to be important mediators of the enhanced fluid reabsorption.

\section{INTRODUCTION}

The progressive destruction of nephrons which characterizes many forms of chronic renal disease leads to specific adaptations in the surviving nephrons which enable the organism to survive despite far advanced renal failure. Such factors as compensatory hypertrophy (1-3), alterations in the rate and distribution of intrarenal blood flow (4-5), the accumulation in the extracellular fluid of organic anions (6-8), and the elaboration of humoral factors which modify renal tubular transport (9-11) have been implicated in the adaptive responses of the diseased kidney. Tubular function under these circumstances may be altered either by adaptations which are intrinsic to the tubular epithelium or to influences which are essentially extrinsic to the nephron. The respective roles of intrinsic vs. extrinsic changes in determining a given functional pattern have hitherto been undefined and it is probable that a delicate interplay between the two elements exists. Consequently, further understanding of nephron function in uremia requires the ability to identify and characterize each of the numerous influences which are exerted upon the surviving nephrons.

The present paper describes a new experimental approach to the study of the functional characteristics of the nephrons of the uremic kidney. Isolated seg- 
ments of single proximal straight tubules obtained from (a) normal rabbits with two intact kidneys, (b) nonuremic rabbits with one "remnant" and one intact kidney, and (c) uremic animals with a solitary "remnant" kidney were perfused in vitro to evaluate changes in the intrinsic functional capacity of the uremic tubules. Each group of nephron segments was studied in an external bathing medium of normal and uremic serum in an effort to examine the effect of a normal vs. uremic environment on their pattern of function. The studies included an estimate of the degree of hypertrophy of the uremic nephrons as well as the influence of uremic serum on fluid secretion in nonperfused nephrons.

All of the data were obtained on superficial proximal straight tubules (PST). ${ }^{1}$ Information about the PST in uremia is of particular interest in that this segment cannot be evaluated adequately by clearance techniques and is inaccessible to micropuncture. Because compensatory hypertrophy is presumed to occur in the PST of the remnant kidney, an effort was made to establish whether a correlation exists between fluid reabsorption and structural growth which is similar to that described for the proximal convoluted tubule $(1,12)$. The studies were also designed to determine whether fluid reabsorption was influenced by the bathing solution. Finally, in view of recent studies which have shown that human uremic serum can convert net fluid reabsorption to net secretion in the PST of normal rabbits (8), the present studies evaluated whether rabbit uremic serum had a similar effect.

The results of the study indicate that PSTs of uremic rabbits with single remnant kidneys reabsorb fluid at a rate which is approximately $70 \%$ greater per unit length than that of normal PSTs. This augmented reabsorptive rate is directly correlated with the process of compensatory hypertrophy of this segment and is not observed in PSTs from nonhpertrophied remnant kidneys. Fluid reabsorption in both normal and uremic PSTs appeared to be an intrinsic property of the tubules and was not altered by the presence or absence of humoral factors in uremic serum. Finally, no evidence for net fluid secretion could be demonstrated.

\section{METHODS}

\section{Experimental groups}

Three groups of animals were used as the source of the PSTs studied. PSTs were obtained from $(a)$ the left kidney of normal rabbits (stage I animals), (b) the remnant kidney of nonuremic rabbits with an intact contralateral kidney

\footnotetext{
${ }^{1}$ Abbreviations used in this paper: BUN, blood urea nitrogen; Jv, net fluid reabsorption; PD, potential difference; PST, proximal straight tubule; SNGFR, single nephron glomerular filtration rate; $U F$, ultrafiltrate.
}

(stage II animals), and (c) the solitary remnant kidney of uremic rabbits (stage III animals). Remnant kidneys were prepared by exposing the posterior surface of the pedicle of the left kidney retroperitoneally via a flank incision and ligating branches of the renal artery so as to infarct approximately $70-85 \%$ of the kidney. In the stage III animals the contralateral kidney was removed during the same procedure. All animals were maintained on a diet of standard rabbit chow and tap water for 1-4 mo before study. Body weight was $3-4 \mathrm{~kg}$ at the time of study and was similar in all three groups.

\section{Dissection of tubules}

The animals were killed by a blow to the back of the neck, the kidneys to be studied were rapidly removed, and a 1-2$\mathrm{mm}$ cross section of cortex was transferred to a bath of chilled normal rabbit serum. Cortical width was measured to the nearest $0.5 \mathrm{~mm}$. Superficial proximal straight tubules were obtained by grasping the tubules close to the corticomedullary junction with fine forceps and dissecting them free in the direction of the outer cortex. A superficial PST was defined as one which joined a proximal convoluted segment in the outermost $0.5 \mathrm{~mm}$ of the cortex. PSTs were dissected with relative ease from both stage II and stage III animals.

\section{Preparation of sera and perfusion solutions}

Normal rabbit serum was obtained commercially (Microbiological Associates, Inc., Walkersville, Md.). Sera from stage II and stage III rabbits were prepared by cannulating the femoral artery at the time of removal of the kidney for dissection and collecting blood into a sterile glass beaker at room temperature. After clotting and centrifugation the serum was decanted and stored at $-4^{\circ} \mathrm{C}$. Before each experiment sera were bubbled with $95 \% \mathrm{O}_{2}-5 \% \mathrm{CO}_{2}$ and the $\mathrm{pH}$ adjusted to 7.4. The osmolality of the normal and stage II sera and of the perfusate (see below) were adjusted to that of the stage III (uremic) serum by addition of urea so that all solutions used in a given experiment were isosmolal. Final osmolality varied from experiment to experiment between 295-330 $\mathrm{mosmol} / \mathrm{kg} \mathrm{H}_{2} \mathrm{O}$. Osmolality was measured with a vapor pressure osmometer (Wescor Inc., Logan, Utah) and was adjusted immediately before each experiment.

An artificial perfusate was designed to simulate end-proximal convoluted tubular fluid (low bicarbonate and free of glucose and amino acids). ${ }^{2}$ This was used in the majority of experiments. The composition of the perfusate was as follows: (in millimoles per liter) $\mathrm{NaCl}, 130 ; \mathrm{NaHCO}_{3}, 5 ; \mathrm{NaAcetate}$, 10; $\mathrm{Na}_{2} \mathrm{HPO}_{4}, 3 ; \mathrm{KCl}, 5 ; \mathrm{MgSO}_{4}, 1.2$; and CaAcetate, 1.8. The $\mathrm{pH}$ was adjusted to 6.7. In certain experiments an ultrafiltrate of uremic (stage III) serum was used as the perfusate. This was prepared by ultrafiltering the serum through a Diaflo XM50 membrane in an ultrafiltration cell (Amicon Corp., Lexington, Mass.) at $4^{\circ} \mathrm{C}$. The $\mathrm{pH}$ of this fluid was also adjusted to 6.7 with $\mathrm{HCl}$.

\footnotetext{
${ }^{2}$ Micropuncture data on the composition of end-proximal tubular fluid are not available for the rabbit. Since fluid reabsorption in the rabbit proximal convoluted tubule (13) appears to be quantitatively similar to that observed in other mammals, the assumption is made that quantitative changes in tubular fluid composition are similar in the two species. The perfusate composition is thus based on data obtained in the rat (14) and the $\operatorname{dog}(15)$.
} 


\section{Perfusion studies}

Free-flow perfusion. Seven normal, eight stage II, and nine stage III PSTs were studied by this method. PST segments 1.1-3.2 $\mathrm{mm}$ in length were transferred to a bath of serum (volume $1.4 \mathrm{ml}$ ) maintained at $37^{\circ} \mathrm{C}$ and bubbled continuously with $95 \% \mathrm{O}_{2}-5 \% \mathrm{CO}_{2}$ and viewed through an inverted microscope at $\times 40-400$. The method of perfusion has been described previously from this laboratory $(10,16)$. Both ends of the tubule were insulated with Sylgard 184 (Dow Corning Corp., Midland, Mich.) [ $\left.\operatorname{carboxy}{ }^{14} \mathrm{C}\right]$ inulin was added to the perfusate $(50 \mu \mathrm{Ci} / \mathrm{ml})$ as an impermeable volume marker. Assuming a normal single nephron glomerular filtration rate (SNGFR) for the rabbit of $20 \mathrm{nl} / \mathrm{min}$ (13) and reabsorption of $60 \%$ of the tubular fluid by the end of the proximal convoluted tubule, the perfusion rate for the PST should be approximately $8 \mathrm{nl} / \mathrm{min}$ for PSTs from normal kidneys and $16 \mathrm{nl} / \mathrm{min}$ for those from stage III remnant kidneys in which SNGFR would be expected to be approximately twice normal, based on rat micropuncture data $(17,18)$. Acordingly in each experimental group approximately one-half the experiments were conducted at the slower perfusion rates $(6-10 \mathrm{nl} / \mathrm{min})$ and one-half at the more rapid rate $(14-20 \mathrm{nl} / \mathrm{min})$. Since perfusion rate did not influence the results (see Tables I-III) the data for each experimental group have been pooled.

In each experiment three sets of observations were made sequentially by changing the type of serum bathing the tubule. Two different sequences used were $(a)$ normal serum, uremic serum, normal serum or $(b)$ uremic serum, normal serum, uremic serum. The mean of the results from the first and third periods were compared with the second period so that any bias resulting from change in the preparation as a function of time was eliminated. Stage II PSTs were studied in normal, uremic, and stage II serum with the order being varied randomly.

Additional experiments were conducted on five normal PSTs bathed in normal serum and four uremic PSTs bathed in uremic serum. Each tubule was perfused sequentially with an ultrafiltrate of normal serum and an ultrafiltrate of uremic serum. The order was varied randomly for each experiment. The osmolality of the two ultrafiltrations and of the bath was identical in each experiment.

In each of the experimental periods a 15 -min period of equilibration was allowed before sample collections were begun. Four-five consecutive timed collections of tubular fluid were made under mineral oil into a constriction pipette which was calibrated at the termination of the experiment.

Samples of tubular fluid were pipetted directly into Aquasol liquid scintillation fluid (New England Nuclear, Boston, Mass.) and total counts per minute measured with a Packard Tricarb liquid scintillation counter (Packard Instrument Co., Inc., Downers Grove, Ill.). Perfusion rate $\left(V_{0}\right)$ was calculated as $\mathrm{V}_{0}=\mathrm{S}_{\mathrm{L}} /\left(\mathrm{S}_{\mathrm{o}}\right) t$ where $\mathrm{S}_{\mathrm{L}}$ is the total amount of isotope collected, $\left(S_{0}\right)$ is the concentration of isotope in the perfusate, and $t$ is the time. Net fluid movement, Jv, expressed as nanoliters per millimeter tubule per min, is thus $\left(\mathrm{V}_{0}-\mathrm{V}_{\mathrm{L}}\right) / \mathrm{L}$ where $V_{L}$ is the collection rate and $L$ is the length of the tubule. Tubule length and internal diameter were measured during perfusion with a calibrated reticle in the ocular of the microscope.

The perfusion pipette which served as a luminal electrode was connected to a calomel half-cell through a $0.16-\mathrm{M} \mathrm{NaCl}$ $4 \%$ agar bridge. The half cell was connected to the input of an impedance converter and the signal displayed on a Grass model 7 polygraph with a model $7 \mathrm{Pl} \mathrm{A}$ low level DC preamplifier (Grass Instrument Co., Quincy, Mass.). The circuit was completed through a $0.16-\mathrm{M} \mathrm{NaCl}-4 \%$ agar bridge connecting the bath to a reference calomel half-cell connected to ground through a precision millivolt reference source (W-P Instruments, Inc., New Haven, Conn.). Any small potential difference due to asymetry of electrodes was nulled before the experiment by means of a variable potentiometer in the impedence converter. Transepithelial potential difference (PD) was monitored continuously throughout the experiment. A correction of $+0.9 \mathrm{mV}$ was made for the liquid junction potential (19). This value was added to the recorded PD to derive the true transtubular PD.

The mean $( \pm \mathrm{SE})$ length of PSTs perfused was $1.83 \pm 0.18$ $\mathrm{mm}$ in normal rabbits, $1.70 \pm 0.20 \mathrm{~mm}$ in stage $\mathrm{II}$, and 1.79 $\pm 0.26 \mathrm{~mm}$ in stage III rabbits.

Stop-flow perfusion. 10 PSTs from stage III rabbits were studied by this method. The arrangement for perfusion followed the method described by Grantham et al (8). The perfusion pipette had a tip diameter of $12-15 \mu \mathrm{m}$; approximately $1 \mathrm{~mm}$ from the tip the internal diameter of the pipet lumen was exactly $75 \mu \mathrm{m}$ over a length of $5 \mathrm{~mm}$. A drop of xylene was sucked into the tip of the perfusion pipette followed by a small amount of perfusate. The tubule was cannulated and perfused for approximately $30 \mathrm{~s}$. A knuckle of tubule near its free end was then sucked into a collecting pipette so as to occlude the lumen. The perfusion pressure was adjusted to $10 \mathrm{~cm} \mathrm{H}_{2} \mathrm{O}$ and remained constant throughout the experiment. Sylgard 184 was used to insure a water-tight seal at the perfusion end. Movement of the oil droplet toward the tubule indicated net fluid reabsorption and movement away from the tubule net secretion.

Net fluid movement was calculated as:

$$
\mathrm{Jv}=\frac{\pi \mathrm{x}}{t \mathrm{~L}} \cdot\left(\frac{\mathrm{ID}}{2}\right)^{2}
$$

where $\mathrm{X}$ is the distance traveled by the oil droplet in time $t$, $L$ is the length of the tubule, and ID is the inner diameter of the pipette. Tubule length and pipette diameter were measured with a calibrated reticle in the ocular of the microscope.

Nonperfused tubules. Grantham and co-workers have demonstrated the phenomenon of lumen expansion in nonperfused PSTs from normal rabbits exposed to human uremic serum (8). The technique described by these workers was used to study fluid secretion in nonperfused tubules. Five-six segments of superficial PSTs from normal and stage III kidneys were dissected from the cortex and transferred in approximately $5 \mu \mathrm{l}$ of normal rabbit serum to each of six empty wells of a Terasaki Microtest tissue culture plate (Falcon Plastics, Div. of Bio(Quest, (Oxnard, Calif.). The tubules were observed at $\times 40-400$ under an inverted microscope. Only tubules which were completely collapsed and without a visible lumen were studied (see Results).

Sera from five uremic rabbits were tested for their ability to stimulate fluid secretion on the tubular segments of each animal. $25 \mu$ l of each test serum was added to each well. 25 $\mu \mathrm{l}$ of normal rabbit serum containing $1 \mathrm{mM} p$-aminohippurate was used as a control in each experiment.

The tissue culture plates were then incubated at $37^{\circ} \mathrm{C}$ in a humidified atmosphere with an ambient gas mixture of $95 \%$ $\mathrm{O}_{2}+5 \% \mathrm{CO}_{2}$. After $15 \mathrm{~min}$ of incubation the PST were inspected for evidence of luminal expansion. Failure to observe expansion in the control segments bathed in $1 \mathrm{mM} p$-aminohippurate was taken as evidence of nomresponsiveness of the particular kidney under study and the experiment discarded. The appearance of a visible lumen in at least two tubules, whether this occurred along the whole length of the tubule or in a segment of it, was taken as positive evidence for secretory activity.

Measurement of tubule dry weight. PSTs obtained from the same kidneys as were studied in the free-flow perfusion 
experiments were employed for measurement of dry weight. A 1-2-mm cross section was transferred to a dish of chilled protein-free Ringers' bicarbonate solution. Superficial PSTs were dissected as described above. A combined length of $8-14 \mathrm{~mm}$ was transferred in a droplet of the dissecting medium to single wells of a tissue culture plate. The tubules were photographed through an inverted microscope at $\times 54$ and were then transferred with fine forceps to a tared piece of aluminum foil and dried for $60 \mathrm{~min}$ in a dry oven at $80^{\circ} \mathrm{C}$. They were then weighed on a Perkin Elmer model AD2 Precision Electronic balance (Perkin-Elmer Corp., Instrument Div., Norwalk, Conn.) (resolution $0.1 \mu \mathrm{g}$ ). The total length of the weighed segments was measured from the photograph. Dry weight was expressed in micrograms per millimeter. Duplicate measurements made on tubules from the same kidney (four observations) varied by less than $10 \%$.

\section{Analytic methods}

Sodium and potassium concentrations of bath and perfusate solutions were measured by flame photometry (Instrumentation Laboratory, Inc., Lexington, Mass.). Chloride concentration was measured with a Radiometer CMT 10 chloride titrator (Radiometer Co., Copenhagen, Denmark). Blood urea nitrogen was measured by the Berthelot method (20). Creatinine concentration was measured with an AutoAnalyzer (Technicon Instruments Corp., Tarrytown, N. Y.). Serum hippurate concentration was measured according to the method of Smith et al. (21). This method detects a number of hippuric acid derivatives (including $m$ - and $p$-aminohippuric acids, $p$-ammophenaceturic acid, $p$-aminophenylsuccinuric acid, $p$-aminobenzoic acid, and $p$-aminomandelic acid). Since the purpose of the assay was to compare hippurate levels between groups of sera rather than to quantitate the absolute levels of any given substance, $p$-aminohipurate was used to set up a standard curve, the colorimetric determination being made at $10 \mathrm{~min}$.

\section{Statistics}

Results of perfusion experiments are expressed as the mean $\pm \mathrm{SE}$ of four-five collections in each experimental period. The mean of the initial plus final periods was compared with the middle period with paired $t$ analysis. When different groups of tubules were compared, an unpaired $t$ test was used.

\section{RESULTS}

\section{Morphology}

Comparably sized remnant kidneys were created in the stage II and the stage III animals. 1-4 mo later the stage II remnant appeared unchanged in size whereas the stage III remnant kidneys had increased in size. The estimated increment was approximately twofold. In comparing the glomeruli and the PSTs obtained from stage III vs. stage I kidneys, both structures were grossly enlarged (Figs. 1 and 2) and occasionally the tubules were distorted in shape with localized areas of dilatation. ${ }^{3}$

\footnotetext{
${ }^{3}$ In isolated cases the surgical procedure appeared to have led to a minor degree of internal hydronephrosis often with small yellowish-brown calculi lying within the pelvi-calyceal
}

\section{Serum analyses}

Sodium, potassium, and chloride concentrations were not significantly different between sera obtained from normal $(150 \pm 2 ; 5.7 \pm 0.5 ; 102 \pm 1.0 \mathrm{meq} / \mathrm{liter})$, stage II $(152 \pm 2 ; 5.9 \pm 0.7 ; 102 \pm 1.2 \mathrm{meq} / \mathrm{liter})$, or stage III rabbits $(15 \mathrm{l} \pm 2 ; 5.9 \pm 0.7 ; 100 \pm 1.2 \mathrm{meq} / \mathrm{liter})$. Blood urea nitrogen (BUN) results are listed in Tables I-III. Serum creatinine concentrations in the three groups were $1.1 \pm 0.4,1.2 \pm 0.6$, and $3.4 \pm 0.4 \mathrm{mg} / 100 \mathrm{ml}$. Mean $\pm \mathrm{SE}$ hippurate concentrations were $0.037 \pm .01 \mathrm{mg} / 100$ $\mathrm{ml}$ in five normal sera and $0.07 \pm .01 \mathrm{mg} / 100 \mathrm{ml}$ in six stage III (uremic) sera.

\section{Tubule dry weight and size}

Dry weights of the PSTs for each experiment are included in Tables I-III and a composite plot of the data is shown in Fig. 3. No difference in weight per unit length was demonstrable in comparing normal with stage II tubules. However, values for the stage III PSTs were significantly greater than either the normal $(P<0.001)$ or the stage II $(P<0.005)$ segments.

The superficial PSTs in all three groups of kidneys were observed to extend from the corticomedullary junction to the outermost cortex. Thus, from measurement of cortical width an approximation of the total length of these segments in each group could be made. Cortical width averaged $2.9 \pm 0.1 \mathrm{~mm}$ in the normal kidneys, $3.3 \pm 0.1 \mathrm{~mm}$ in the stage II kidneys, and $4.6 \pm 0.2$ $\mathrm{mm}$ in the stage III kidneys. PSTs from the latter group of kidneys were thus greatly increased in length. An additional assessment of the relative size of the tubules was obtained from measurements of the internal diameter during perfusion. The values were as follows: normal $22.3 \pm 0.5 \mu \mathrm{m}$; stage II, $24.1 \pm 1.5 \mu \mathrm{m}$; and stage III, $31.5 \pm 0.8 \mu \mathrm{m}$. The internal diameter of stage III PSTs was significantly greater than the former two groups $(P<0.005)$. Thus, all parameters of tubule size (dry weight, length, and internal diameter) indicate marked hypertrophy.

\section{Net fluid reabsorption}

\section{FREE-FLOW PERFUSION}

Normal PSTs (Table I). Net fluid reabsorption was $0.41 \pm 0.05 \mathrm{nl} / \mathrm{mm}$ per min in a bath of normal serum and $0.37 \pm 0.07 \mathrm{nl} / \mathrm{mm}$ per min in uremic serum. These

system. In these kidneys the PSTs often had patent lumens at the time of dissection. After incubation in normal rabbit serum for $30 \mathrm{~min}$, the lumens remained patent; stop-flow perfusion did not reveal evidence of net fluid secretion and the patency, which was never observed in normal PSTs, is presumably attributable to a combination of structural hypertrophy and long standing distention. Apart from three tubules used in stop-flow perfusion experiments, none of the PSTs with a patent lumen was used for functional studies. 

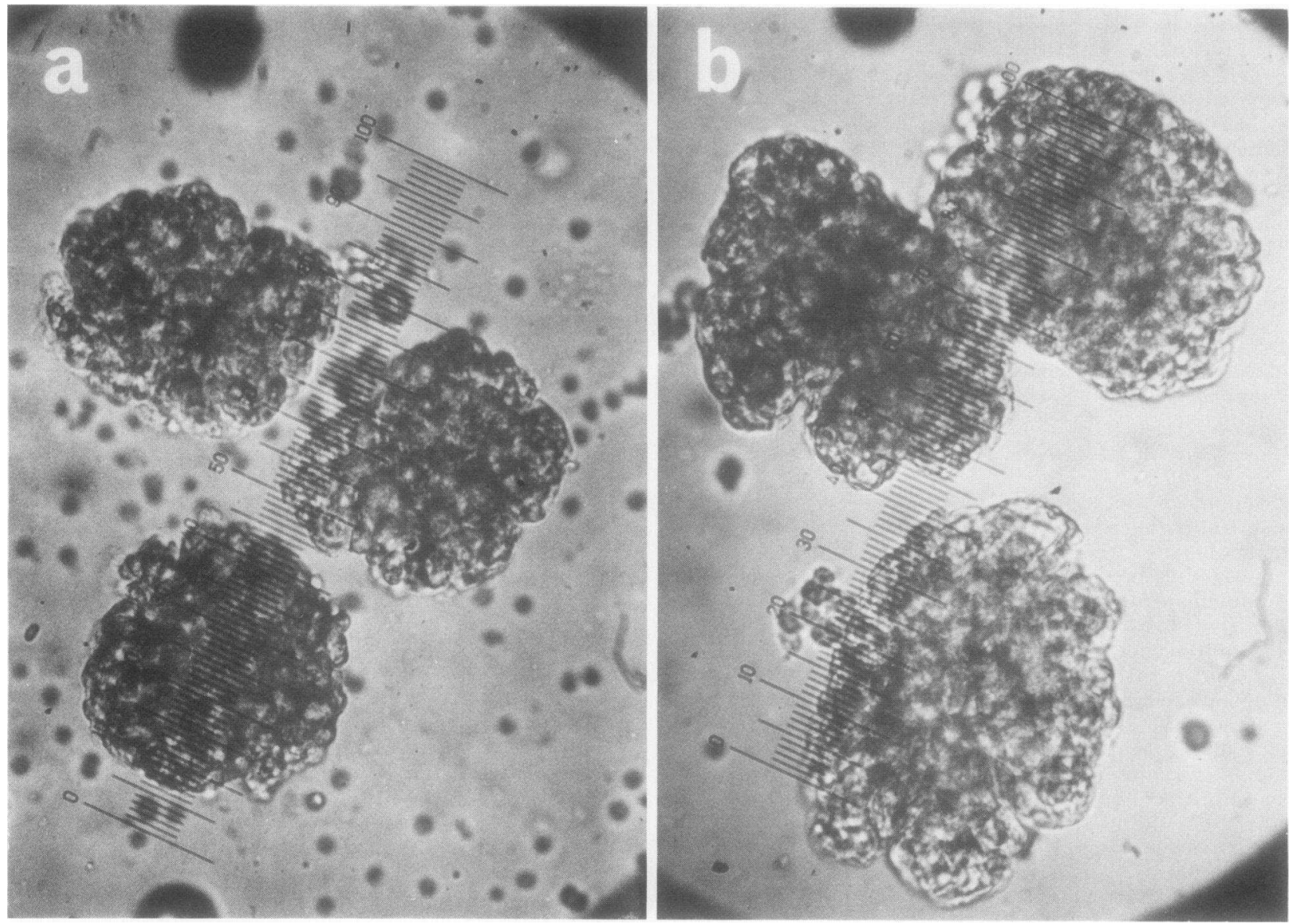

FiguRE 1 Isolated glomeruli from ( $a$ ) a normal rabbit kidney and $(b)$ a uremic remnant kidney photographed at the same magnification, showing marked hypertrophy of the latter.

values are not significantly different from each other. Transepithelial PD averaged $+1.5 \pm 0.3 \mathrm{mV}$ (lumen positive) in normal serum and $+1.5 \pm 0.2 \mathrm{mV}$ in uremic serum.

Stage II PSTs (Table II). Net fluid reabsorption was $0.45 \pm 0.55 \mathrm{nl} / \mathrm{mm}$ per min in normal serum, $0.41 \pm 0.05$ $\mathrm{nl} / \mathrm{mm}$ per min in uremic serum, and $0.37 \pm 0.06 \mathrm{nl} / \mathrm{mm}$ per min in stage II serum. There is no significant difference between any of these values. Transepithelial $\mathrm{PD}$ was $+0.3 \pm 0.2 \mathrm{mV}$ (lumen positive) in normal serum and $+0.6 \pm 0.2 \mathrm{mV}$ in uremic serum and $0.5 \pm 0.2 \mathrm{mV}$ in stage II serum.

Stage III PSTs (Table III). Net fluid reabsorption was $0.67 \pm 0.04 \mathrm{nl} / \mathrm{mm}$ per min in a normal serum bath and $0.73 \pm 0.05 \mathrm{nl} / \mathrm{mm}$ per min in a uremic serum bath. These results are not significantly different from each other. Transepithelial PD was $-0.4 \pm 0.3 \mathrm{mV}$ (lumen negative) in normal serum and $-0.4 \pm 0.3 \mathrm{mV}$ in uremic serum. The values for net fluid reabsorption where an ultrafiltrate of uremic serum was used as the per- fusate (see asterisks in Tables I-III) were not distinguishable from the results with the artificial perfusate.

A comparison of net fluid reabsorptive rates between the three experimental groups is shown in Fig. 4. It may be seen that the stage III PSTs absorbed fluid at a rate which was approximately $70 \%$ greater than both normal and stage II PSTs.

The data from all tubules studied indicated that there was a significant correlation between net fluid reabsorption and dry weight per unit length $(r=0.6958$; $P<0.0005)$.

Influence of normal vs. uremic serum ultrafiltrate (UF) as perfusate. An ultrafiltrate of both normal and uremic serum was used to perfuse each of five normal and four uremic PSTs. In normal PSTs, Jv was 0.40 $\pm 0.02 \mathrm{nl} / \mathrm{mm}$ per min with normal UF and $0.39 \pm 0.03$ $\mathrm{nl} / \mathrm{mm}$ per min with uremic UF. In uremic PSTs, Jv was $0.66 \pm 0.02 \mathrm{nl} / \mathrm{mm}$ per min with normal UF and $0.70 \pm 0.05 \mathrm{nl} / \mathrm{mm}$ per min with uremic UF. Neither of these differences is significant. 


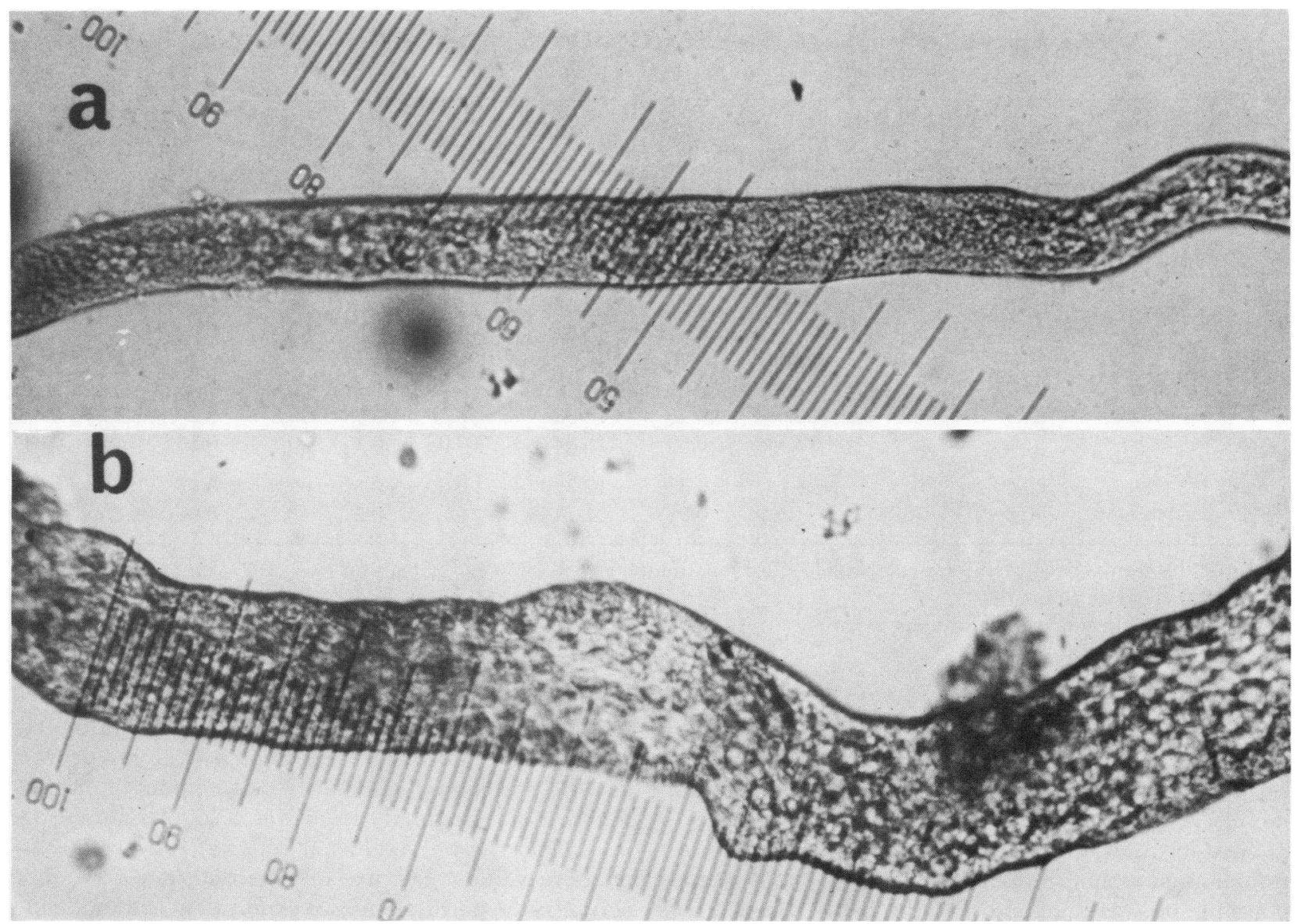

FIGURE 2 Nonperfused superficial proximal straight tubules from $(a)$ a normal kidney and $(b)$ a uremic remnant kidney photographed at the same magnification. The uremic segment is grossly hypertrophied and has an irregular outer border.

TABLE I

Size, Dry Weight, Transtubular PD, and Net Fluid Reabsorption of Superficial PSTs of Normal Rabbits

\begin{tabular}{|c|c|c|c|c|c|c|c|c|c|}
\hline & \multirow[b]{2}{*}{ BUN } & \multirow{2}{*}{$\begin{array}{l}\text { Kidney } \\
\text { cortical } \\
\text { width }\end{array}$} & \multirow{2}{*}{$\begin{array}{l}\text { Internal } \\
\text { diameter }\end{array}$} & \multirow{2}{*}{$\begin{array}{c}\text { Dry } \\
\text { weight }\end{array}$} & \multirow{2}{*}{$\begin{array}{l}\text { Perfusion } \\
\text { rate }\end{array}$} & \multicolumn{2}{|c|}{ PD } & \multicolumn{2}{|c|}{$\begin{array}{l}\text { Net fluid } \\
\text { reabsorption }\end{array}$} \\
\hline & & & & & & NS & us & NS & US \\
\hline & $\mathrm{mg} / 100 \mathrm{ml}$ & $m m$ & $\mu m$ & $\mu g / m m$ & $n l / m i n$ & \multicolumn{2}{|c|}{$m V$} & \multicolumn{2}{|c|}{$n l / m m / m i n$} \\
\hline & 15.8 & 2.5 & 22.0 & 0.67 & 6.73 & +2.4 & +2.1 & 0.67 & 0.78 \\
\hline & 15.0 & 2.5 & 22.4 & 0.56 & 7.21 & +0.7 & +0.7 & 0.40 & 0.25 \\
\hline & 15.7 & 3.0 & 22.2 & 0.58 & $7.22 *$ & +1.5 & +1.0 & 0.31 & 0.25 \\
\hline & 17.3 & 3.0 & 24.1 & 0.62 & 9.90 & +1.1 & +1.6 & 0.47 & 0.20 \\
\hline & 16.8 & 3.0 & 20.8 & 0.41 & 14.36 & +1.1 & +1.1 & 0.31 & 0.35 \\
\hline & 17.0 & 2.5 & 24.1 & 0.60 & 16.31 & +2.5 & +2.5 & 0.33 & 0.38 \\
\hline & 15.8 & 3.5 & 20.6 & 0.58 & $18.24^{*}$ & +1.2 & +1.4 & 0.36 & 0.34 \\
\hline Mean & 16.2 & 2.9 & 22.31 & 0.57 & 11.42 & +1.5 & +1.5 & 0.41 & 0.37 \\
\hline$\pm \mathrm{SE}$ & 0.3 & 0.1 & 0.53 & 0.03 & 1.82 & 0.3 & 0.2 & 0.05 & 0.07 \\
\hline
\end{tabular}

Potential difference is corrected for calculated liquid junction potential. NS = normal serum bath; US $=$ uremic serum bath.

* Ultrafiltrate of uremic serum used as perfusate. 
TABLE II

Size, Dry Weight, Transtubular PD, and Net Fluid Reabsorption of Superficial PSTs of Remnant Kidneys of Stage II (Nonuremic) Rabbits

\begin{tabular}{|c|c|c|c|c|c|c|c|c|c|c|c|c|}
\hline & Duration & & Kidney & & & & & PD & & Net & id reabs & rption \\
\hline & surgery & BUN & width & diameter & weight & rate & NS & US & St II S & NS & US & St II S \\
\hline & mo & $m g / 100 \mathrm{ml}$ & $m m$ & $\mu m$ & $\mu g / m m$ & nl/min & & $m V$ & & & $l / m m / m i r$ & \\
\hline & 2.5 & 25.5 & 3.0 & 24.4 & 0.62 & 6.01 & +0.4 & +0.7 & +0.5 & 0.36 & 0.39 & 0.37 \\
\hline & 3.3 & 22.1 & 3.5 & 22.8 & 0.62 & 6.78 & +0.6 & +0.6 & +0.6 & 0.49 & 0.25 & 0.13 \\
\hline & 2.5 & 24.9 & 3.5 & 28.9 & 0.62 & $9.00^{*}$ & +1.2 & +1.9 & +1.9 & 0.39 & 0.43 & 0.37 \\
\hline & 2.3 & 21.4 & 4.0 & 24.4 & 0.64 & 10.22 & +0.4 & +0.5 & +0.5 & 0.44 & 0.41 & 0.38 \\
\hline & 1.6 & 22.9 & 3.0 & 22.2 & 0.75 & 14.10 & -1.1 & -0.4 & -0.6 & 0.75 & 0.69 & 0.69 \\
\hline & 0.8 & 24.3 & 3.5 & 31.1 & 0.65 & $16.44^{*}$ & +0.4 & +1.1 & +0.4 & 0.35 & 0.48 & - \\
\hline & 1.3 & 22.9 & 3.0 & 20.8 & 0.46 & 17.38 & +0.8 & +0.8 & +0.8 & 0.28 & 0.37 & 0.34 \\
\hline & 2.5 & 23.5 & 3.0 & 17.8 & 0.69 & 18.54 & +0.3 & +0.1 & +0.1 & 0.56 & 0.24 & 0.31 \\
\hline Mean & 2.1 & 23.4 & 3.3 & 24.1 & 0.63 & 12.31 & +0.3 & +0.6 & +0.5 & 0.45 & 0.41 & 0.37 \\
\hline$\pm \mathrm{SE}$ & 0.3 & 0.5 & 0.1 & 1.5 & 0.03 & 1.74 & 0.2 & 0.2 & 0.2 & 0.05 & 0.05 & 0.06 \\
\hline
\end{tabular}

Potential difference is corrected for calculated liquid junction potential. NS = normal serum bath; US = uremic serum bath; St II S = stage II serum bath.

* Ultrafiltrate of uremic serum used as perfusate.

\section{STOP-FLOW PERFUSION}

The effects of rabbit uremic serum on net fluid reabsorption in proximal straight tubules from nine uremic rabbits is illustrated in Fig. 5. The experimental sequence for each tubule was normal serum, uremic serum, normal serum. In four experiments, $1 \mathrm{mM} p$-aminohippurate was then added to the bath. Three of the tubules had patent lumina before perfusion. All tubules, including those with patent lumina, demon- strated net fluid reabsorption when bathed in normal rabbit serum $(0.22 \pm 0.2 \mathrm{nl} / \mathrm{mm}$ per $\mathrm{min})$. Net fluid reabsorption in uremic serum was $0.15 \pm 0.04 \mathrm{nl} / \mathrm{mm}$ per min and the postcontrol value after replacement of the uremic serum by normal serum was $0.20 \pm .03 \mathrm{nl} / \mathrm{mm}$ per min. There is no significant difference between any of these values. The use of an ultrafiltrate of uremic serum as the perfusate in two experiments did not yield results which differed from the remainder of the experiments. Net fluid secretion in uremic serum was ob-

TABLE III

Size, Dry Weight, Transtubular PD, and Net Fluid Reabsorption of Superficial PSTs of the Solitary Remnant Kidney of Stage III (Uremic) Rabbits

\begin{tabular}{|c|c|c|c|c|c|c|c|c|c|c|}
\hline & \multirow{2}{*}{$\begin{array}{l}\text { Duration } \\
\text { post- } \\
\text { surgery }\end{array}$} & \multirow[b]{2}{*}{ BUN } & \multirow{2}{*}{$\begin{array}{l}\text { Kidney } \\
\text { cortical } \\
\text { width }\end{array}$} & \multirow{2}{*}{$\begin{array}{c}\text { Internal } \\
\text { diameter }\end{array}$} & \multirow{2}{*}{$\begin{array}{c}\text { Dry } \\
\text { weight }\end{array}$} & \multirow{2}{*}{$\begin{array}{l}\text { Perfusion } \\
\text { rate }\end{array}$} & \multicolumn{2}{|c|}{ PD } & \multicolumn{2}{|c|}{$\begin{array}{l}\text { Net fluid } \\
\text { reabsorption }\end{array}$} \\
\hline & & & & & & & NS & US & NS & US \\
\hline & mo & $\mathrm{mg} / 100 \mathrm{ml}$ & $m m$ & $m m$ & $\mu \mathrm{g} / \mathrm{mm}$ & $n l / m i n$ & \multicolumn{2}{|c|}{$m V$} & \multicolumn{2}{|c|}{$\mathrm{nl} / \mathrm{mm} / \mathrm{min}$} \\
\hline & 2.3 & 71.0 & 4.5 & 32.0 & 1.81 & 7.66 & +0.1 & -0.3 & 0.79 & 0.87 \\
\hline & 3.8 & 97.1 & 4.5 & 29.2 & 1.06 & 7.88* & +0.1 & +0.5 & 0.60 & 0.75 \\
\hline & 0.8 & 28.6 & 5.0 & 31.1 & 1.36 & 7.42 & +0.1 & +0.3 & 0.87 & 0.89 \\
\hline & 3.9 & 180.0 & 5.0 & 31.1 & 0.75 & 8.63 & -1.5 & +0.5 & 0.71 & 0.63 \\
\hline & 3.8 & 35.0 & 4.0 & 32.7 & 1.49 & 10.12 & -1.9 & -1.9 & 0.72 & 0.64 \\
\hline & 1.6 & 35.0 & 4.5 & 24.0 & - & 16.54 & -0.3 & -0.5 & 0.53 & 0.95 \\
\hline & 0.8 & 20.0 & 5.0 & 26.4 & 0.89 & $17.22^{*}$ & +0.2 & -1.6 & 0.71 & 0.74 \\
\hline & 4.0 & 71.9 & 5.0 & 33.3 & 0.79 & 19.91 & +0.1 & +0.1 & 0.70 & 0.59 \\
\hline & 1.6 & 63.2 & 4.0 & 34.2 & 1.25 & 20.02 & -0.5 & -0.7 & 0.46 & 0.53 \\
\hline Mean & 2.5 & 66.9 & 4.6 & 31.5 & 1.18 & 12.37 & -0.4 & -0.4 & 0.67 & 0.73 \\
\hline$\pm \mathrm{SE}$ & 0.5 & 16.4 & 0.1 & 0.8 & 0.13 & 1.77 & 0.3 & 0.3 & 0.04 & 0.05 \\
\hline
\end{tabular}

Potential difference is corrected for calculated liquid junction potential. NS = normal serum bath; US = uremic serum bath. * Ultrafiltrate of uremic serum used as perfusate. 


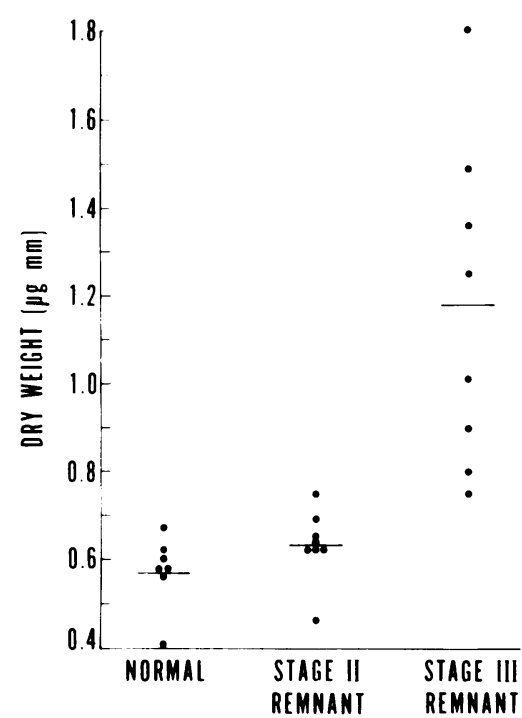

Figure 3 A comparison of the dry weight/unit length of superficial proximal straight tubules from normal rabbit kidneys, remnant kidneys of nonuremic rabbits (stage II), and remnant kidneys of uremic rabbits (stage III).

served in only one experiment. $1 \mathrm{mM} p$-aminohippurate in the bath resulted in net fluid secretion in all four experiments in which it was used.

\section{NONPERFUSED TUBULES}

The results of incubation of PSTs from the five normal and five uremic rabbits in rabbit uremic serum are shown in Table IV. PSTs from each animal were incubated in five different uremic rabbit sera and one normal serum containing $1 \mathrm{mM} p$-aminohippurate. In each experiment lumen expansion was induced by 1 $\mathrm{mM} p$-aminohippurate. Uremic rabbit serum had no consistent secretory effect. Lumen expansion was observed in only $4 / 25$ assays on normal tubules and 3/25 assays on uremic tubules.

\section{DISCUSSION}

A logical requirement for the further elucidation of the multitude of factors which influence renal tubular function in uremia is an experimental model which is able to discriminate between intrinsic tubular functions and influences which are essentially extrinsic to the nephron. The model described in this study utilized isolated nephron segments from normal and chronically diseased kidneys, each being exposed to both a normal and a "uremic" milieu. With this new experimental approach, fluid reabsorption was studied in PSTs of uremic rabbits with single remnant kidneys. The function of this nephron segment in uremia has not been previously characterized largely due to its inaccessibility to micropuncture.

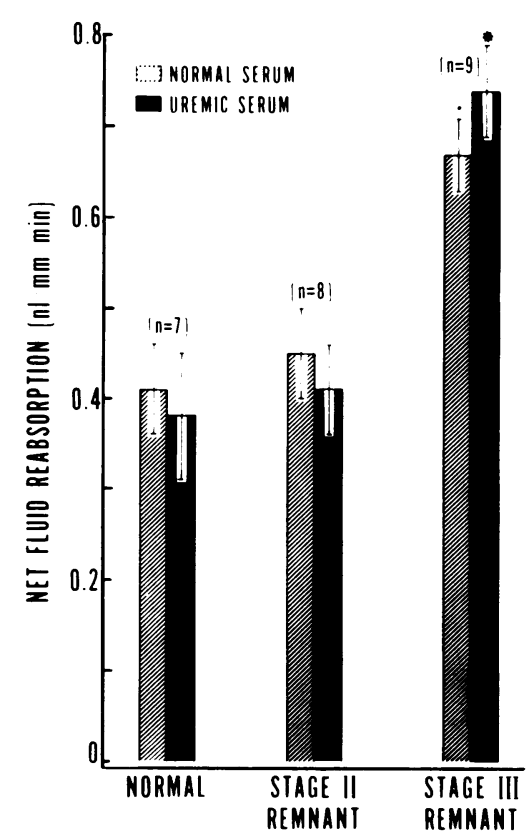

FIgURE 4 A comparison of net fluid reabsorption per millimeter of superficial proximal straight tubule from normal rabbit kidneys, remnant kidneys of nonuremic rabbits (stage II), and remnant kidneys of uremic rabbits (stage III) showing the effect of normal and uremic rabbit serum. ${ }^{*} P<0.005 \mathrm{vs}$. normal and stage II.

The requirements for fluid reabsorption in the PST are best viewed in the light of observations made on the proximal convoluted tubule in uremia. In nonglomerular diseases such as pyelonephritis $(22,23)$, partial nephrectomy, i.e., "remnant" kidneys $(3,17,18)$ and uninephrectomy $(1,3)$ in which the SNGFR of

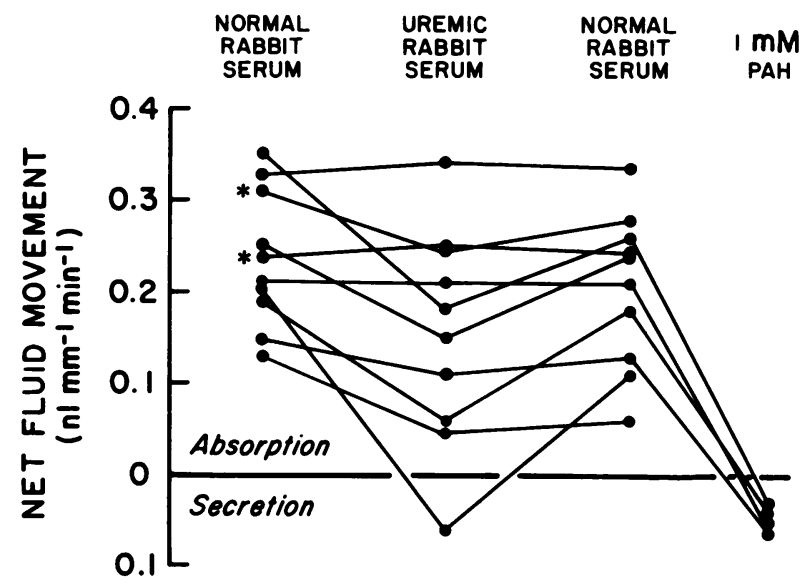

Figure 5 Net fluid movement in uremic proximal straight tubules perfused by stop-flow methods and exposed to a peritubular bathing medium of normal rabbit serum, uremic rabbit serum, and normal rabbit serum containing $1 \mathrm{mM} p$-aminohippurate $(\mathrm{PAH}) .{ }^{*}$ Indicates experiments in which an ultrafiltrate of uremic serum was used as the perfusate. 


\section{TABLE IV}

Net Fluid Secretion in Nonperfused Superficial PSTs of Normal and Uremic Rabbits Incubated in Uremic Rabbit Sera

\begin{tabular}{|c|c|c|c|c|c|c|c|c|c|c|}
\hline \multirow[b]{2}{*}{ BUN } & \multicolumn{5}{|c|}{$\begin{array}{l}\text { Normal PSTs } \\
\text { Rabbit no. }\end{array}$} & \multicolumn{5}{|c|}{$\begin{array}{c}\text { Uremic (Stage III) PSTs } \\
\text { Rabbit no. }\end{array}$} \\
\hline & $\mathrm{N}_{1}$ & $\mathrm{~N}_{2}$ & $\mathbf{N}_{3}$ & $\mathrm{~N}_{4}$ & $\mathrm{~N}_{5}$ & $\mathrm{U}_{1}$ & $\mathrm{U}_{2}$ & $\mathrm{U}_{3}$ & $\mathrm{U}_{4}$ & $\mathrm{U}$ \\
\hline \multicolumn{11}{|l|}{$m g / 100 \mathrm{ml}$} \\
\hline 53.7 & - & - & + & - & - & - & - & + & - & - \\
\hline 70.1 & - & + & - & - & - & - & - & - & - & - \\
\hline 66.1 & - & - & - & - & - & - & - & - & - & - \\
\hline 62.6 & - & - & - & - & + & - & + & - & - & - \\
\hline 50.8 & - & - & - & + & - & - & -.- & + & - & - \\
\hline \multicolumn{11}{|l|}{$p$-aminohip- } \\
\hline purate, $1 \mathrm{mM}$ & + & + & + & + & + & + & + & + & + & + \\
\hline
\end{tabular}

Lumen expansion indicates net secretion of fluid.

${ }^{+}$, Lumen expansion; - , no visible lumen.

the surviving nephrons consistently increases, absolute fluid reabsorption by the accessible portion of the proximal convoluted tubule also increases $(1,18)$. Associated with this functional adaptation are the structural changes of compensatory hypertrophy $(1,12)$. In these disease states, delivery of tubular fluid to the PSTs is increased because fractional reabsorption by the proximal convoluted tubule is normal or decreased ( 1 , 17, 22-24). Thus, if the adaptive phenomena are consistent throughout the length of the proximal tubule, the rate of fluid reabsorption should increase in the PSTs of the uremic remnant kidney.

The enhanced reabsorptive capacity of the proximal convoluted tubule does not appear to be a response to an increased tubular flow rate per se since acute reduction in nephron mass results in an increase in SNGFR with no change in absolute reabsorption by the proximal tubule $(25,26)$. It appears, therefore, that the phenomenon is related either to the chronicity of the elevation in SNGFR or more probably to the development of compensatory hypertrophy of the tubule.

In none of the above-mentioned studies have observations been extended to the pars recta. This segment of the proximal tubule not only has a reabsorptive function but an important secretory one (27), and the control of net fluid movement may well be determined by the balance between these processes.

In the present studies PSTs from the remnant kidneys of uremic rabbits were perfused in vitro and their function compared with the same segments derived from normal kidneys and from remnant kidneys of nonuremic animals.

Net fluid reabsorption per unit length of tubule was approximately $0.7 \mathrm{nl} / \mathrm{mm}$ per min in stage III PSTs vs. approximately $0.4 \mathrm{nl} / \mathrm{mm}$ per min in normal and stage II PSTs. Associated with this increment of approximately $70 \%$ in reabsorptive rate was a marked degree of structural hypertrophy such that a significant correlation was found between fluid reabsorption and the dry weight per unit length of tubule. The latter increased by nearly twofold in the stage III segments. The values for net fluid reabsorption in the normal PSTs closely approximated those observed by other workers (28-30) as did those of the PSTs derived from remnant kidneys of nonuremic animals. The data from this latter group of nephron segments, which did not undergo compensatory hypertrophy, provides clear evidence that the alteration in reabsorptive function was not a feature of the remnant kidney or the surgical procedure per se but was related to the uremic state and(or) structural hypertrophy.

Although it is tempting to relate the enhanced reabsorptive rate of the hypertrophied tubules to the observed increase in luminal surface area, such a correlation may lead to erroneous conclusions because the PST is lined by a brush border epithelium, the surface area of which greatly exceeds the measured diameter as determined by light microscopy. Nevertheless, it is of interest to note that stage III PSTs show an increase in $\mathrm{Jv}$ of $70 \%$, an increase in dry weight of $100 \%$, and an increase in luminal area of $40 \%$, all parameters being factored for length. Since these observed increments are not identical it is possible that some selectivity of adaptation occurs which is determined not only by tubular mass but by other unidentified factors.

An additional factor of importance and one which strengthens the close relationship between fluid reabsorption and tubular size in the uremic PSTs was the observation that the reabsorptive rate of the PSTs was not influenced by the humoral environment of the tubule. In all three groups, reabsorptive rates and transepithelial PD remained constant despite differences in the peritubular bathing medium. Uremic sera had no influ- 
ence on the reabsorptive rates of normal PSTs and the enhanced reabsorption by the uremic PSTs was likewise unaffected by normal serum. These observations exclude an important role for undefined constituents of uremic serum on fluid reabsorption by the PST. They do not, however, exclude the modifying role of other extratubular factors, such as alterations in peritubular Starling forces which may result from changes in the distribution of intrarenal blood flow in the remnant kidney (4).

Fluid reabsorption was not affected by differences in perfusion rates or by the use of an ultrafiltrate of uremic serum as the perfusate. These observations would suggest that changes in tubular fluid flow rate in the physiological range and in the range anticipated to occur in the remnant kidney (see Methods) are not important modulators of fluid reabsorption in this segment. Likewise unidentified constituents of uremic serum which are filtered at the glomerulus (i.e., comparable to the ultrafiltrate used) do not play an important role in this process.

The role of organic anions in altering fluid transport by the PST has been recently reviewed by Grantham (31) and the influence of uremic serum on the renal transport of hippurates has been well documented (6$8)$. The PST secretes substances such as $p$-aminohippurate at a rate which is three times as great as that of the proximal convoluted tubule (27) and significant isosmolal fluid secretion may be coupled to this transport process (32). Human uremic serum applied to the peritubular surface of nonperfused PSTs or PSTs perfused by stop-flow will convert a process of net fluid reabsorption to one of net secretion $(8,33)$. Since the maximal rate of tubular transport of PAH per GFR is elevated in animals with chronic renal failure (34), it was important to evaluate the contribution of this factor in the present studies.

Net fluid secretion was evaluated not only in nonperfused tubules and under stop-flow perfusion as described previously (8), but also under the more physiological conditions of free-flow perfusion. In these experiments uremic rabbit PSTs were exposed to uremic rabbit serum. The importance of examining uremic serum from an animal of the same species stems from the observation in the studies of Grantham et al. that normal human serum significantly depresses the rate of fluid reabsorption by rabbit PSTs, a phenomenon which may be related to different levels of organic anions in human serum or to some other undefined interspecies incompatibility (32). In the present studies conducted under the same stop-flow conditions as described by Grantham et al. (32) net secretion was consistently absent. Indeed, no difference in reabsorptive rate was evident whether the tubule was exposed to normal or to uremic serum. The difference between this observation and that described for human uremic serum may lie in differences in the levels of organic anions (e.g., hippurates) or of other unidentified substances which exist in higher concentrations in human uremic serum. We are led to conclude, however, that at least for the rabbit, organic anion secretion plays litthe if any role in modulating fluid reabsorption by the PST of the uremic animal.

The transepithelial potential differences of stage III PSTs were lower than those by the normal PSTs (i.e., less lumen positive). Although no information is provided by this study as to the reason for this difference, the observation would suggest that fluid reabsorption may be driven by different mechanisms in the stage III tubules or that differential permselectivity to ionic species may be altered in these segments.

The results of the present studies conclusively demonstrate that fluid reabsorption by the PST of the remnant kidney of uremic rabbits is markedly increased. This adaptation is due to an intrinsic alteration in the function of the tubular epithelium and is closely linked to the process of compensatory hypertrophy. The enhanced reabsorptive rate presumably facilitates the reabsorption of the increased load of tubular fluid delivered to this nephron segment by the convoluted portion of the proximal tubule in remnant kidneys with elevated values for SNGFR. It should not be construed that this functional adaptation is universal to all forms of chronic renal disease and the conclusions drawn from this study must obviously relate to the remnant kidney until further observations on other forms of renal disease become available. In experimental chronic glomerulonephritis, for example, SNGFR is normal or diminished (35-37) and a parallel reduction in absolute fluid reabsorption by the proximal convoluted tubule occurs $(35,36)$. By analogy, fluid reabsorption in the PST should remain constant or diminish in parallel with the change in SNGFR in these diseased states, but these data are not available.

Simplistically it would seem, therefore, that the same stimulus which leads to hypertrophy of glomerular function leads to a comparable increase in tubular function, and whether this relationship holds throughout the nephron remains to be evaluated.

\section{ACKNOWLEDGMENTS}

These studies were supported by grants 7 R01 AM 19822 and IT 32 AM 07205 from the National Institutes of Health.

\section{REFERENCES}

1. Hayslett, J. P., M. Kashgarian, and F. H. Epstein. 1968. Functional correlates of compensatory renal hypertrophy. J. Clin. Invest. 47: 774-782.

2. Weinman, E. J., K. Renquist, R. Stroup, M. Kashgarian, and J. P. Hayslett. 1973. Increased tubular reabsorption of sodium in compensatory renal growth. Am. J. Physiol. 224: $565-571$.

3. Kaufman, J. M., H. J. DiMeola, N. J. Siegel, B. Lytton, 
M. Kashgarian, and J. P. Hayslett. 1974. Compensatory adaptation of structure and function following progressive renal ablation. Kidney Int. 6: 10-17.

4. Carriere, S., N. L. M. Wong, and J. H. Dirks. 1973. Redistribution of renal blood flow in acute and chronic reduction of renal mass. Kidney Int. 3: 364-371.

5. Sawabu, N., E. Takazakuru, A. Handa, A. Shinoda, A. Takada, and J. Takeuchi. 1972. Intrarenal vascular changes in experimental glomerulonephritis. Kidney Int. 1: 89-99.

6. Preuss, H. G., S. G. Massry, J. R. Maker, M. Gilliece, and G. E. Schreiner. 1966. Effects of uremic sera on renal tubular p-aminohippurate transport. Nephron. 3: 265273.

7. Orringer, E. P., F. R. Weiss, and H. G. Preuss. 1971. Azotemic inhibition of organic anion transport in the kidney of the rat: Mechanisms and characteristics. Clin. Sci. (Oxf.). 40: $159-169$.

8. Grantham, J. J., R. L. Irwin, P. B. Qualizza, D. R. Tucker, and F. C. Whittier. 1973. Fluid secretion in isolated proximal straight renal tubules. Effect of human uremic serum. J. Clin. Invest. 52: 2441-2450.

9. Bricker, N. S., R. W. Schmidt, H. Favre, L. G. Fine, and J. J. Bourgoignie. 1975. On the biology of sodium excretion: The search for a natriuretic hormone. Yale J. Biol. Med. 48: 293-303.

10. Fine, L. G., J. J. Bourgoignie, K. H. Hwang, and N. S. Bricker. 1976. On the influence of the natriuretic factor from patients with chronic uremia on the bioelectric properties and sodium transport of the isolated mammalian collecting tubule. J. Clin. Invest. 58: 590-597.

11. Fine, L. G., J. J. Bourgoignie, H. Weber, and N. S. Bricker. 1976. Enhanced end-organ responsiveness of the uremic kidney to the natriuretic factor. Kidney Int. 10: 364-372.

12. Arrizurieta de Muchnik, E. E., E. M. Lipham, and C. W. Gottschalk. 1969. Form and function in normal and hypertrophied nephrons. In Compensatory Renal Hypertrophy. W. W. Nowinski and R. J. Goss, editors. Academic Press, Inc., New York. 29-42.

13. Chonko, A. M., R. W. Osgood, A. E. Nickel, T. F. Ferris, and J. H. Stein. 1975. The measurement of nephron filtration rate and absolute reabsorption in the proximal tubule of the rabbit kidney. J. Clin. Invest. 56: 232-235.

14. Gottschalk, W., W. E. Lassiter, and M. Mylle. 1960. Localization of urine acidification in the mammalian kidney. Am. J. Physiol. 198: 581-585.

15. Clapp, J. R., J. F. Watson, and R. W. Berliner. 1963. Osmolality bicarbonate concentration and water reabsorption in the proximal tubule of the dog nephron. Am.J. Physiol. 205: 273-280.

16. Fine, L. G., and W. Trizna. 1977. Influence of prostaglandins on sodium transport of isolated medullary nephron segments. Am. J. Physiol. 232: F383-390.

17. Schultze, R. G., F. Weisser, and N. S. Bricker. 1972. The influence of uremia on fractional sodium reabsorption by the proximal tubule of rats. Kidney Int. 2: 59-66.

18. Weber, H., K. Y. Lin, and N. S. Bricker. 1975. Effect of sodium intake on single nephron glomerular filtration rate and sodium reabsorption in experimental uremia. Kidney Int. 8: 14-20.

19. Cardinal, J., M. D. Lutz, M. B. Burg, and J. Orloff. 1975. Lack of relationship of potential difference to fluid reabsorption in the proximal renal tubule. Kidney Int. 7: $94-$ 102 .
20. Mattenheimer, H. 1970. Micromethods for the Chemical and Biochemical Laboratory. Ann Arbor Science Publishers, Inc., Ann Arbor, Mich. 2nd edition. 126-127.

21. Smith, H. W., N. Finkelstein, L. Aliminosa, B. Crawford, and M. Graber. 1945. The renal clearance of substituted hippuric acid derivatives and other aromatic acids in dog and man. J. Clin. Invest. 24: 388-404.

22. Lubowitz, H., M. L. Purkerson, and N. S. Bricker. 1966. Investigation of single nephrons in the chronically diseased (pyelonephritic) kidney of the rat using micropuncture techniques. Nephron. 3: 73-79.

23. Bank, N., and H. S. Aynedjian. 1966. Individual nephron function in experimental pyelonephritis. I. Glomerular filtration rate and proximal tubular sodium, potassium and water. J. Lab. Clin. Med. 5: 713-727.

24. Wen, S. F., N. L. M. Wong, R. L. Evanson, E. A. Lockhart, and J. H. Dirks. 1973. Micropuncture studies of sodium transport in the remnant kidney of the dog. The effect of graded volume expansion. J. Clin. Invest. 52: 386397.

25. Allison, M. E. M., E. M. Lipham, E. W. Lassiter, and C. W. Gottschalk. 1973. The acutely reduced kidney. Kidney Int. 3: 354-363.

26. Diezi, J., P. Michoud, A. Grandchamp, and G. Giebisch. 1976. Effects of nephrectomy on renal salt and water transport in the remaining kidney. Kidney Int. 10: 450-462.

27. Tune, B. M., M. B. Burg, and C. S. Patlak. 1969. Characteristics of p-aminohippurate transport in proximal renal tubules. Am. J. Physiol. 217: 1057-1063.

28. Burg, M. B., and J. Orloff. 1968. Control of fluid absorption in the renal proximal tubule. J. Clin. Invest. 47: 20162024.

29. Schafer, J. A., S. L. Troutman, and T. E. Andreoli. 1974. Volume reabsorption, transepithelial potential differences and ionic permeability properties in mammalian superficial proximal straight tubules. J. Am. Physiol. 64: $582-607$.

30. Schafer, J. A., and T. E. Andreoli. 1976. Anion transport processes in mammalian superficial proximal straight tubule. J. Clin. Invest. 58: 500-513.

31. Grantham, J. J. 1976. Fluid secretion in the nephron: Relation to renal failure. Physiol. Rev. 56: 248-258.

32. Grantham, J. J., P. B. Qualizza, and R. L. Irwin. 1974. Net fluid secretion in proximal straight renal tubules in vitro: Role of PAH. Am. J. Physiol. 226: 191-197.

33. Fine, L. G., and N. S. Bricker. 1976. A re-examination of the influence of uremic serum on net fluid movement across proximal straight tubules of the rabbit. Clin. Res. 24: 399A. (Abstr.)

34. Rieselbach, R. E., L. Todd, M. Rosenthal, and N. S Bricker. 1964. The functional adaptation of the diseased kidney. II. Maximum rate of transport of PAH and the influence of acetate. J. Lab. Clin. Med. 64: 724-730.

35. Rocha, A., M. Marcondes, and G. Malnic. 1973. Micropuncture study in rats with experimental glomerulonephritis. Kidney Int. 3: 14-23.

36. Allison, M. E. M., C. B. Wilson, and C. W. Gottschalk. 1974. Pathophysiology of experimental glomerulonephritis in rats. J. Clin. Invest. 53: $1402-1423$.

37. Lubowitz, H., D. C. Mazumdar, J. Kawamura, J. T. Crosson, F. Weisser, D. Rolf, and N. S. Bricker. 1974. Experimental glomerulonephritis in the rat: Structural and functional observations. Kidney Int. 5: 356-364. 